\title{
Playing the con game of academe
}

\author{
Lives in Science: How Institutions Affect \\ Academic Careers \\ by Joseph C. Hermanowicz \\ University of Chicago Press: 2009. \\ 344 pp. $\$ 45$
}

Young scientists often aim for research-focused professorships at elite universities. Those who achieve this goal spend their lives tirelessly working towards the next great finding, hopeful of recognition from their scientific peers. Other graduates take academic jobs at lessprestigious colleges and universities, where they may divide their careers between research, service, teaching and outside pursuits. Who is happier in the end?

In Lives in Science, sociologist Joseph Hermanowicz examines the career paths and overall satisfaction of a small group of physicists using an innovative longitudinal research method. In 1994, he interviewed 60 randomly selected tenured and tenure-track physicists at six universities across the United States. The results were published in his 1998 book The Stars Are Not Enough: Scientists - Their Passions and Professions. Ten years later,

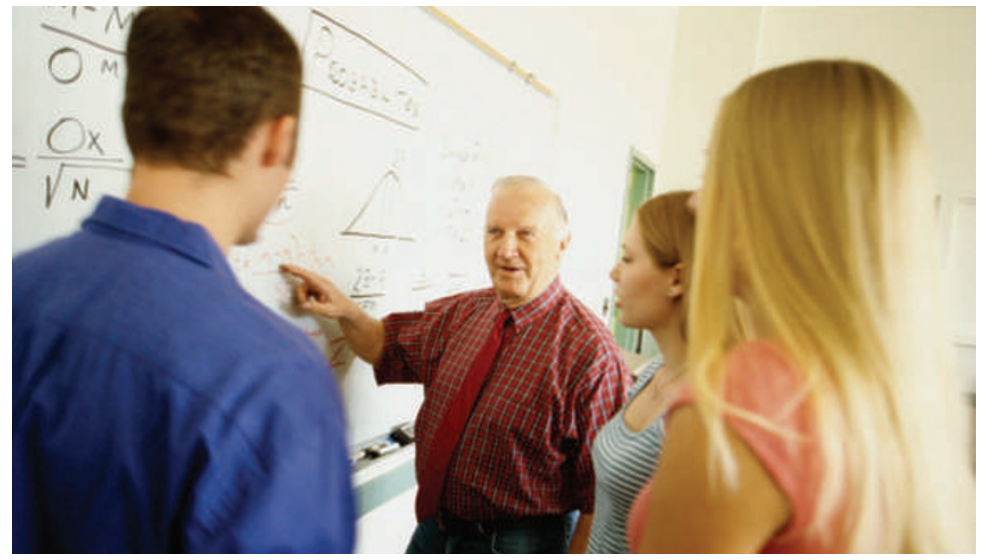

Scientists who teach at less-prestigious universities are more satisfied at retirement than those at elite institutions because they had more realistic career expectations. earned theirs between 1970 and 1980; and 'late-career' scientists were PhDs before 1970. Ten years later, the physicists had all moved up a group, with the late-career group moving into a new category - 'post career', consisting of those near or at retirement.

The physicists are also categorized into three groups based on their workplaces: 'elite' research universities, 'pluralist' universities that "place a premium on both research and teaching" and 'communitarian' universities that emphasize "teaching in the presence of research". Hermanowicz, like many qualitative researchers, allows the respondents to define

the realization that the scientific recognition for which they had striven so long would now go to younger scientists. For the first time, this elite group's "expectations for their careers exceed reality" and their satisfaction was low.

The study is grounded in the theories and methods of sociology, which may be unfamiliar to readers from the natural sciences. Hermanowicz bases his comparison on Erving Goffman's 1952 analysis of how individuals reconcile their expectations, which are socially produced, with the reality that society limits the ability to achieve those expectations. Also applied is the concept of anomie, first outlined by the French sociologist Emile Durkheim in the late nineteenth century: a loss of societal norms that results from people's expectations for the future exceeding the realities of life. People can experience the disillusionment of anomie in various aspects of their lives, but for scientists it occurs when the desire to achieve recognition from one's peers exceeds the opportunities to do so.

Hermanowicz makes many assumptions. He assumes, as do the physicists in his study, that research is the highest form of scholarly endeavour. He refers to teaching as an undesirable activity — as "acceptable unproductivity”. In focusing solely on academics, Hermanowicz ignores the vast numbers Hermanowicz interviewed the same scientists again to assess how their careers had changed in the interim. He recorded their number of publications, career focus, aspirations, orientation to work and focus on work as opposed to family.

Hermanowicz likens academic careers to a 'con game' in which faculty members are victims. The process starts in graduate school, where students in all academic disciplines are reverentially taught about the exemplary research of those who have excelled in the field.

\section{"Students in academic disciplines all start out expecting to achieve greatness; but few do."}

their own institution types, which may differ from the more objective rankings of the US National Research Council. This allows him to identify overlapping categories, such as individual scientists who behave like members of an elite while working at a pluralist university.

Hermanowicz finds that a faculty member's level of career satisfaction at retirement depends on the prestige of their institution and the scientific reputation they are able to achieve. Those at less-prestigious universities, who were also more likely to have graduated from similar They learn to emulate the pantheon of great researchers. Thus, all start out expecting to achieve greatness; but few do so. Robbed of the status and recognition they once sought, physicists at less-prestigious universities must learn to console themselves.

The scientists are compared by age. In his 1998 analysis, Hermanowicz defined three groups: 'early career' included those who earned PhDs after 1980; 'middle career' scientists institutions, were generally satisfied because of the balance they ultimately achieved in their lives. Like other academics, they had once hoped to achieve scientific greatness, but quickly realized that such recognition would elude them. They dealt with disappointment about their career paths early on.

By contrast, physicists who got the early prize of an elite university job were satisfied with their careers - until the end. Then they were hit with of physicists who work outside academia. If it is the ability to achieve scientific recognition that delivers career satisfaction, as he argues, then perceptions might evolve differently in government labs and in private industry. These researchers, too, would once have expected to join the scientific pantheon but have taken other roles. How have they adjusted their expectations to more restricted research avenues?

Lives in Science reveals that all scientists are socially conditioned to contribute substantially to the knowledge base and expect to receive recognition for it. But all must reconcile themselves to the shortcomings of the academic game. With research pressure growing in less-prestigious universities, and with limited resources, anomie will remain with us. Its cure is to require graduate institutions to present a more realistic picture of what it means to be a scientist.

Rachel Ivie is a sociologist and assistant director of the Statistical Research Center at the American Institute of Physics, 1 Physics Ellipse, College Park, Maryland 20740, USA. e-mail: rivie@aip.org 